\title{
Smoking-related warning messages formulated as questions positively influence short-term smoking behaviour
}

Journal of Health Psychology

2016, Vol. 2I(I) 60-68

(C) The Author(s) 2014

Reprints and permissions:

sagepub.co.uk/journalsPermissions.nav DOI: $10.1177 / 1359105314522083$

hpq.sagepub.com

@SAGE

\author{
Barbara CN Müller',2, Simone M Ritter², Sabine \\ Glock $^{3}$, Ap Dijksterhuis ${ }^{2}$, Rutger CME Engels ${ }^{2}$ \\ and Rick B van Baaren²
}

\begin{abstract}
Research demonstrated that by reformulating smoking warnings into questions, defensive responses in smokers are reduced and smoking-related risk perception increases. We explored whether these positive outcomes can be generalised to actual behaviour. Participants saw either a movie presenting subheadings with smoking-related questions or statements. Afterwards, the time was measured until participants lit their first cigarette. Smokers who were presented with questions about the harms of smoking waited longer before lighting up a cigarette than smokers who were presented with statements. Presenting questions instead of the statements seems to be an effective means to prolonging smokers' abstinence.
\end{abstract}

\section{Keywords}

self-persuasion, short-term abstinence, smoking, warning labels

Tobacco use is the leading cause of death across the world (Murray and Lopez, 1997). For health and consumer rights reasons, governments mandate several tobacco control initiatives. Current anti-smoking campaigns mainly focus on providing people with information about the risks and consequences of smoking (e.g. 'Smoking causes lung cancer'). One of the most prominent anti-smoking campaigns consists of the use of health-related warning labels. Research has shown that in the last 50 years, advertisement for cigarettes shifted from cigarettes being displayed to the cigarette box only, with the cigarette box becoming an effective vehicle for advertising (Dewe et al., 2013). Therefore, warning labels on cigarette packages seemed a promising tool to provide smokers with health messages. These warning labels are not only presented on cigarette packages but also in cigarette advertisements. Warning labels as fear appeals aim to induce such an amount of fear that smokers' motivation to quit should increase (Kempf and Harmon, 2006). Therefore, health campaigns often rely on threatening,

\footnotetext{
'Ludwig Maximilian University Munich, Germany

${ }^{2}$ Behavioural Science Institute, Radboud University

Nijmegen, The Netherlands

3 University of Luxembourg, Luxembourg

\section{Corresponding author:}

Barbara CN Müller, Behavioural Science Institute,

Radboud University Nijmegen, P.O. Box 9104, $6500 \mathrm{HE}$

Nijmegen, The Netherlands.

Email: B.Muller@psych.ru.nl
} 
fear-inducing and extreme language to persuade people to stop unhealthy behaviour (Good and Abraham, 2007).

Correlational research on the effectiveness of warning labels has provided substantial evidence for their positive influence on smokers (e.g. Borland et al., 2009). However, some researchers call for abolishing fear appeals and call them useless (e.g. Ruiter and Kok, 2005). Recently, threatening warning labels have been shown to lead to defensive responses (e.g. Glock et al., 2013; Glock and Kneer, 2009; Kessels et al., 2010; for an overview see Albarracin et al., 2006), especially if self-efficacy is low (Peters et al., 2012). Threatening warning labels also lead to less accurate recognition of the messages (Leshner et al., 2011) and a decrease in attention allocation (Kessels et al., 2011). Furthermore, presenting people with drastic arguments against smoking can arouse the impression that one's 'freedom to choose' is threatened, which may lead to psychological reactance (e.g. Brehm and Sensenig, 1966; Grandpre et al., 2003) and to a decreased probability of quitting smoking (Wolburg, 2006). The vast majority of smokers is by now well aware of the dangers of tobacco use (Hastings and MacFadyen, 2002; Tuakli et al., 1990), and despite the fact that many smokers are highly motivated to quit smoking (Burt and Peterson, 1998), only one-third who tried to stop smoking in 2006 were successful in the Netherlands. Furthermore, knowledge about the harmful consequences is not related to desires to quit (Lipkus et al., 2013). The aim of this study was to improve the effectiveness of the current fear-inducing warning statements by reformulating them into questions, a method that can be applied in various anti-smoking campaigns.

Whereas the role of self-persuasion and selfperception in persuasion is emphasised in theoretical models (e.g. Elaboration Likelihood Model; Petty and Cacioppo, 1986), as well as by empirical findings (e.g. Bem, 1967; Mussweiler and Neumann, 2000), current warning labels do not consider these aspects. This is very surprising, as the literature on social influence has shown that self-persuasion is more effective than external persuasion (Aronson, 1999; Craig and Blankenship, 2006; Maio and Thomas, 2007). For example, Mussweiler and Neumann (2000) demonstrated that arguments provided by an external source are less convincing than arguments deliberated by oneself. This is due to people's tendency to correct for information provided by an external but not internal source. While judgmental correction is typical for externally provided arguments, people seemingly fail to correct for the influence of self-generated arguments. Furthermore, research has shown that health messages are more persuasive when involvement is high (Braverman, 2008). By reformulating statements into questions, the involvement of thinking about the topic might be increased, and intrinsic motivation enhanced (Senay et al., 2010). It has been shown that a proper mean to increase the effectiveness of health messages is to reformulate statements by questions (Godin et al., 2012), and recent research demonstrated that warning labels formulated as questions positively influence smoking-related risk perception (Glock et al., 2013). When participants were confronted with statements or graphic warning labels, their smoking-related risk perception decreased, suggesting a defensive response. This, however, was not the case when participants were confronted with warning labels formulated as questions. In addition, research on self-perception has shown that people make inferences on their inner states by observing their behaviour (Bem, 1967). Smokers who witness themselves arguing against smoking may, therefore, be more convinced that smoking is harmful than smokers who are given the same information by an external source.

This study builds on the evidence for the use of questions in anti-smoking campaigns. However, given the small attitude-behaviour association in socially undesirable, risky behaviour (Fazio and Towles-Schwen, 1999), it is necessary to investigate changes in actual smoking behaviour. Previous research has shown that participants who generated and wrote down arguments as to why smoking is bad abstained longer from lighting a cigarette 
Table I. Personal characteristics. Results are demonstrated as mean scores $(M)$, standard deviations (SD) and percentages.

\begin{tabular}{|c|c|c|c|}
\hline & $\begin{array}{l}\text { Self-involvement } \\
(N=21)\end{array}$ & $\begin{array}{l}\text { No self-involvement } \\
(N=19)\end{array}$ & Effects \\
\hline & $M(S D)$ & $M(S D)$ & \\
\hline $\begin{array}{l}\text { Number of cigarettes } \\
\text { smoked per day }\end{array}$ & $10.83(1.23)$ & $10.77(1.26)$ & $F(I, 46)=0.00 I, p=.98$ \\
\hline $\begin{array}{l}\text { Number of cigarettes } \\
\text { smoked on the day of the } \\
\text { experiment }\end{array}$ & $3.83(0.44)$ & $3.42(0.45)$ & $F(I, 46)=0.45, p=.97$ \\
\hline Attempts to give up smoking & I.2I (0.28) & $1.70(0.28)$ & $U=222, p=.16$ \\
\hline $\begin{array}{l}\text { Intention to quit smoking } \\
\text { (Yes-answers) }\end{array}$ & $54.17 \%(n=13)$ & $62.50 \%(n=15)$ & $\chi^{2}(I)=0.34, p=.56$ \\
\hline $\begin{array}{l}\text { Number of years they } \\
\text { smoked }^{\text {a }}\end{array}$ & $6.54(0.87)$ & $8.33(0.98)$ & $U=231.50, p=.34$ \\
\hline
\end{tabular}

aln the 'no self-involvement' condition: $n=18$, as one participant refused to provide this information.

than those who merely read anti-smoking arguments (Müller et al., 2009). Although these findings are very promising, it remains difficult to apply them to current anti-smoking campaigns. Using a paper-and-pencil-based method to increase smokers' self-involvement is complicated and almost impossible to implement in anti-smoking campaigns outside a therapeutic setting.

Previous research has shown that warning labels formulated as questions positively influence smoking-related risk perception (Glock et al., 2013), and that generating as compared to reading arguments against smoking can lead to prolonged abstinence (Müller et al., 2009). In the present article, different lines of research were combined to develop an anti-smoking media campaign that can be easily applied and has the potential to become far reaching. We tested whether presenting individuals with questions about smoking (i.e. encouraging them to think about the consequences of smoking) leads to prolonged abstinence. We observed participants smoking behaviour after they watched a movie in which either smoking-related statements or smoking-related questions were implemented. By doing so, this study aimed to investigate whether replacing statements by questions can increase the effectiveness of warning labels in anti-smoking campaigns. Moreover, we were interested whether our manipulation can be applied in a more subtle way that can be applied in anti-smoking media campaigns. Therefore, we did not present the sentences on an empty computer screen, but implemented them in a movie.

\section{Method}

\section{Participants and design}

A total of 48 students (37 female, $M_{\text {age }}=23.8$ years, standard deviation $\left(S D_{\text {age }}\right)=3.9$ years, age range $=19-41$ years) participated for course credits or financial compensation. As accessed by a questionnaire that participants completed after the experiment, all participants were daily smokers: 29.2 per cent smoked 1-5 cigarettes/ day, 25 per cent $6-10$ cigarettes/day and 45.8 per cent 11-20 cigarettes/day, and no differences in personal and demographic characteristics were found between conditions (Table 1). A between-subjects factor design (movie with questions vs statements) was used, with time of abstinence (in minutes) as dependent variable. Participants were randomly assigned to one of the two conditions. 


\section{Procedure}

The experiment took place in a bar lab, a naturalistic setting where smoking is allowed (Harakeh et al., 2007). Participants were asked to sit at a small table where, in addition to some magazines, a glass with cigarettes and a lighter were placed. They were informed that the experiment consisted of three small and unrelated parts, and that the total duration of the experiment was about 35 minutes. As a cover story, participants were told that the first part investigates the influence of smoking on memory. They were instructed to smoke a cigarette while trying to remember 10 words written on a paper. The real aim of this first part was to reduce the degree to which observed smoking behaviour was moderated by differences in craving (see Harakeh et al., 2007).

Thereafter, participants were seated in front of a television and were asked to attentively watch a movie that would last for 9 minutes. We decided to present the movie 'Earth', a documentary about nature and animals, as we wanted to present a movie without an emotional plot. Furthermore, to keep the movie as neutral as possible, the voice of the narrator was replaced by classical music.

In order to manipulate participants' selfinvolvement, we assembled five sentences into the movie. In the self-involvement as well as the no self-involvement condition, the topics of the sentences were the same, but the syntax differed between the two conditions. In the self-involvement condition, the sentences were formulated as questions (e.g. 'Why can smoking have negative health effects?', 'Why is it good to stop smoking?', 'Who could you ask for help to quit smoking?'), whereas in the no self-involvement condition, the sentences were presented as statements ('Smoking can have negative health effects', 'Smoking can cause fatal lung cancer', 'Find help to quit smoking: Consult your physician or pharmacist'). All sentences were written with white letters on a black banner, and each of the five banners appeared on the lower part of the screen for 5 seconds. The presentation of the sentences was equally distributed across the 9 minutes, and the topics of the sentences were unrelated to the movie. Three of the sentences were about smoking, one about animal experiments and one about nuclear energy, with the latter two used as filler items to distract attention from smoking.

Later, the movie participants were told that the last experiment involves a short computer task, and that it will take some time before they can proceed as the experimenter has some problems with the computer. Furthermore, participants were told that while waiting they have to stay in the room, and that they can do and take whatever they want. The information that the participants can take whatever they want was given to make sure that the participants feel free to take a cigarette out of the glass that was still standing on the table from the first part of the experiment.

In the observation room, the experimenter timed the minutes until the participants started to smoke. At the moment the participants lit up a cigarette, the observation and time measure stopped. For participants who did not light up a cigarette within 30 minutes, the observation and time measure stopped after 30 minutes, and the participant was, as in previous research (Müller et al., 2009), ascribed a score of 30 minutes. The experimenter, then, entered the room and told the participants that the computer was not working correctly, and that they could not complete the third task.

Finally, participants answered a questionnaire concerning personal background (age and gender), smoking habits (number of cigarettes smoked per day, number of cigarettes smoked on the day of the experiment, number of years smoked and number of attempts to quit smoking), and whether they had a clue what the experiment is about. After completing the questionnaire, all participants were thanked, debriefed and paid. The total time of the experiment varied, depending on how long participants waited before smoking another cigarette. The first two parts of the study took about 15 minutes, and we waited another 30 minutes before approaching the participant (in case they did not start to smoke). Thus, the length of the experiment varied between 25 and 50 minutes 
Table 2. Descriptive statistics of the dependent variable 'Time until a cigarette was lit'. Results are demonstrated as mean scores (M); standard deviations (SD); No cigarette lit; and 25, 50, and 75 percentiles.

\begin{tabular}{lll}
\hline & Self-involvement $(N=21)$ & No self-involvement $(N=19)$ \\
\hline Mean score $(M)$ & 25.816 & 16.97 \\
$S D$ & 9.166 & 13.951 \\
No cigarette lit & 16 & 9 \\
Percentile & & \\
$\quad 25$ & 26.560 & 2.000 \\
50 & 30.000 & 21.230 \\
75 & 30.000 & 30.000 \\
\hline
\end{tabular}

(including a final short questionnaire concerning demographics).

\section{Results and discussion}

Seven participants were excluded from the analysis as they did not believe the cover story, and one participant was excluded because he smoked during the manipulation. A KolmogorovSmirnov test revealed that the dependent variable, 'time until a cigarette was lit', was not normally distributed, $D(40)=.38, p<.001$. Therefore, a Mann-Whitney U test was conducted to test the hypothesis that participants in the question condition refrained longer from smoking than participants in the statement condition. The movie had a significant effect on abstinence, $U=135.00, p=.04, r=-.32$. Participants who were shown a movie presenting smoking-related questions waited longer before lighting up a cigarette (median $=30.00$ minutes) than participants who were shown a movie presenting smoking-related statements (low self-involvement) (median $=21.33 \mathrm{~min}$ utes). Further information about the distribution of the dependent variable 'time until a cigarette was lit' is provided in Table 2. The current findings suggest that presenting questions also positively influences observed smoking behaviour.

\section{General discussion}

The aim of this study was to improve the effectiveness of cigarette warning labels by a method applicable to current anti-smoking campaigns. Results demonstrated that showing smokers a movie presenting questions about the harms of smoking or quitting smoking leads to longer abstinence from smoking than showing a movie presenting statements about why smoking is harmful. Thereby, questions do not necessarily be related to the content of the movie.

This method is not only easily applicable, it also has the potential to become far reaching. Warning labels are frequently required on tobacco products and in tobacco advertisements. For example, by 1991, 77 countries called for health warnings on tobacco products and recently the Framework Convention for Tobacco Control (FCTC; World Health Organization (WHO), 2003) stated that warning labels 'should be $50 \%$ or more of the principal display areas but shall be no less than $30 \%$ of the principal display areas' (Article 11). Given these strong requirements, it can be assumed that questions placed on warning labels reach smokers every time they buy a pack or take a cigarette. In addition, presenting questions as subheadings in movies may also be highly effective in cigarette advertisements in cinemas.

Besides its good applicability to anti-smoking campaigns, the current method has further advantages. First, presenting statements with arguments against risky behaviour can lead to defensive reactions that may even undermine the goals of anti-smoking efforts (Agostinelli and Grube, 2003; Albarracin et al., 2006; Glock et al., 2013; Kessels et al., 2010), whereas 
questions are less likely to give people the impression that their 'freedom to choose' is threatened (Brehm and Sensenig, 1966; Grandpre et al., 2003). In addition, questions not only increase the persuasion of the arguments due to their self-generated character (Aronson, 1999; Craig and Blankenship, 2006; Godin et al., 2012; Maio and Thomas, 2007), they also allow for finding arguments the individual smoker is able to accept. This diminishes the threatening content of anti-smoking campaigns, making defensive responses and reactance less likely: the answers are only as threatening and as fear inducing as the smoker allows them to be. Recent research in this domain already demonstrated that perceived threat of graphic and textual warning labels influences attention towards these messages (Süssenbach et al., 2013). Another explanation for the present findings could be the role of cognitive dissonance (Festinger, 1957). When the self-image is threatened, it is argued that people experience cognitive dissonance. By reformulating statements into questions, the warning labels might have illicit less cognitive dissonance; thus, the selfimage is less threatened, which leads to less defensive responses and thus less smoking.

It has to be kept in mind that self-efficacy is of special importance when it comes to threatening health messages: If self-efficacy is high, threatening messages become more likely to work (Peters et al., 2012). Unfortunately, in this study, no measures of self-efficacy were collected. As our student population did only consist of light smokers (with a mean of 10 cigarettes per day) and only between one and two stop attempts, it could be speculated whether self-efficacy in our sample was low. Thus, whether the threatening statements were less effective than the less threatening questions needs further investigation. In future research, measures of self-efficacy should definitely be included to clarify the influence of self-efficacy in the present design. Additionally, other important aspects that influence the perception of health messages should be taken into account when further investigating the appropriateness of questions instead of statements on warning labels. For example, it has been shown that smokers attend more to coping information compared to high-risk information (Ruiter and Kok, 2005).

Third, it is possible that the statements currently used are, via operant conditioning, linked to the rewards of smoking. This suggests that the statements originally meant to prevent people from smoking may, after a while, function as smoking-related cues that activate reward networks (Hutchison et al., 2002). This idea is supported by functional magnetic resonance imaging (fMRI) research, which has shown that presenting smokers with smoking-related cues activates a distributed reward-signalling network (David et al., 2005). These existing links could possibly be extinguished by replacing statements by questions. To avoid that the questions also become smoking-related cues, it is important to use a variety of questions, and to substitute them regularly by new questions. Partly, the present findings might be due to the novelty of the questions compared to the statements. However, Glock et al. (2013) compared the effects of questions with effects of graphic warning labels, which were both new for participants of their study: they were neither familiar with the graphic warning labels nor with the questions. While the threatening pictures led to a decrease in smoking-related risk perception, questions did not have such an effect. This speaks against the novelty explanation.

For future research, it may be interesting to include a baseline condition in which participants are provided with smoking-unrelated statements. By now we know that participants who read questions about why smoking is harmful waited longer before lighting up a cigarette than participants who were presented with statements about the harms of smoking. A baseline condition can shed light on whether questions lead to an increase, or statements to a decrease, in time. Additionally, influences on the relation between smoking beliefs and expectations to smoke should be explored (Fitz et al., 2013). Concerning the time of abstinence, it might also be interesting to investigate the influence on long-term smoking behaviour. 
Given that the identity as a smoker influences the way persuasive messages are perceived and integrated (Falomir-Pichastor et al., 2002), the question rises whether light and heavy smokers are differently influenced by levels of selfinvolvement. The current sample did not include many 'pack-a-day' smokers, which makes it difficult to answer this question. In follow-up research, the sample size could be increased to shed light on the question whether highly committed smokers are more sensitive to persuasive methods that require higher levels of selfinvolvement, or whether highly committed smokers feel threatened, and, therefore, response with defensive coping strategies and increased reactance (Liberman and Chaiken, 1992). Furthermore, mainly female participants were tested in this study, and follow-up should guaranty a more mixed sample. Another important point that needs to be addressed is that although the topic of the questions and statements were similar, the content differ between conditions, with statements containing more threatening information than the used questions. Further research should control for this possible confound by including two conditions, a question condition containing threatening information (e.g. 'Can smoking cause fatal lung cancer?') versus a statement without threatening information (e.g. 'It is good to stop smoking').

The current findings may also be applied in campaigns that focus on other health-related issues (e.g. overweight and inactivity). However, replacing statements by questions only works for health issues where people are aware of the negative effects of the unwanted behaviour. Therefore, the first step should always be to inform people about the consequences of the undesirable behaviour. However, when this knowledge is established, presenting questions instead of statements may be used in various media campaigns that aim to change unwanted attitudes and behaviour.

\section{Acknowledgements}

We thank Miranda van Berlo, Lonneke Debets, Anna Maaskant and Sanne Pennings for their help in data collection.

\section{Funding}

This research received no specific grant from any funding agency in the public, commercial or not-forprofit sectors.

\section{References}

Agostinelli G and Grube J (2003) Tobacco counteradvertising: A review of the literature and a conceptual model for understanding effects. Journal of Health Communication 25: 31-40.

Albarracin D, Durantini MR and Earl A (2006) Empirical and theoretical conclusions of an analysis of outcomes of HIV-prevention interventions. Current Directions in Psychological Science 15: 73-78.

Aronson E (1999) The power of self-persuasion. American Psychologist 54: 875-884.

Bem DJ (1967) Self-perception: An alternative interpretation of cognitive dissonance phenomena. Psychological Review 74: 183-200.

Borland R, Wilson N, Fong GT, et al. (2009) Impact of graphic and text warnings on cigarette packs: Findings from four countries over five years. Tobacco Control 18: 358-364.

Braverman J (2008) Testimonial versus informational persuasive messages: The moderating effect of delivery mode and personal involvement. Communication Research 35: 666-694.

Brehm JW and Sensenig J (1966) Social influence as a function of attempted and implied usurpation of choice. Journal of Personality and Social Psychology 4: 703-707.

Burt RD and Peterson AV (1998) Smoking cessation among high school seniors. Preventive Medicine 27: 319-327.

Craig TY and Blankenship KL (2006) Language and persuasion: Linguistic extremity influences message processing and behavioral intentions. Journal of Language and Social Psychology 30: 290-310.

David SP, Munafo MR, Johansen-Berg H, et al. (2005) Ventral striatum/nucleus accumbens activation to smoking-related pictorial cues in smokers and nonsmokers: A functional magnetic resonance imaging study. Biological Psychiatry 58: 488-494.

Dewe M, Ogden J and Coyle A (2013) The cigarette box as an advertising vehicle in the United Kingdom: A case for plain packaging. Journal of Health Psychology. Epub ahead of print 22 October 2013. DOI: $10.1177 / 1359105313504236$. 
Falomir-Pichastor JM, Invernizzi F, Mugny G, et al. (2002) Social influence on intention to quit smoking: The effect of the rhetoric of an identity-relevant message. International Review of Social Psychology 15: 81-96.

Fazio RH and Towles-Schwen T (1999) The MODE model of attitude-behavior processes. In: Chaiken S and Trope Y (eds) Dual Process Theories in Social Psychology. New York: Guilford Press, pp. 97-116.

Festinger L (1957) A Theory of Cognitive Dissonance. USA: Stanford University Press.

Fitz CC, Kaufman A and Moore PJ (2013) Lay theories of smoking and young adult nonsmokers' and smokers' smoking expectations. Journal of Health Psychology. Epub ahead of print 29 October 2013. DOI: $10.1177 / 1359105313502694$.

Glock S and Kneer J (2009) Are deterrent pictures effective? The impact of warning labels on cognitive dissonance in smokers. Applied Psychology: Health and Well-Being 1: 356-373.

Glock S, Müller BCN and Ritter SM (2013) Warning labels formulated as questions positively influence smoking related risk perception. Journal of Health Psychology 18: 252-262.

Godin G, Bélanger-Gravel A, Vézina-Im L-A, et al. (2012) Question-behaviour effect: A randomised controlled trial of asking intention in the interrogative or declarative form. Psychology \& Health 27: 1086-1099.

Good A and Abraham C (2007) Measuring defensive responses to threatening messages: A meta-analysis of measures. Health Psychology Review 1: 208-229.

Grandpre J, Alvaro EM, Burgoon M, et al. (2003) Adolescent reactance and anti-smoking campaigns: A theoretical approach. Health Communication 15: 349-366.

Harakeh Z, Engels RCME, Van Baaren RB, et al. (2007) Imitation of cigarette smoking: An experimental study on smoking in a naturalistic setting. Drug and Alcohol Dependence 86: 199-206.

Hastings $G$ and MacFadyen L (2002) The limitations of fear messages. Tobacco Control 11: 73-75.

Hutchison KE, LaChance H, Niaura R, et al. (2002) The DRD4 VNTR polymorphism influences reactivity to smoking cues. Journal of Abnormal Psychology 111: 14-143.

Kempf DS and Harmon SK (2006) Examining the effectiveness of proposed cigarette package warning labels with graphic images among U.S. college students. Academy of Marketing Studies Journal 10: 77-93.
Kessels LTE, Ruiter RAC and Jansma BM (2010) Increased attention but more efficient disengagement: Neuroscientific evidence for defensive processing of threatening health information. Health Psychology 29: 346-354.

Kessels LTE, Ruiter RAC, Brug J, et al. (2011) The effects of tailored and threatening nutrition information on message attention. Evidence from an event-related potential study. Appetite 56: 32-38.

Leshner G, Bolls P and Wise K (2011) Motivated processing of fear appeals and disgust images in televised anti-tobacco ads. Journal of Media Psychology 23: 77-89.

Liberman A and Chaiken S (1992) Defensive processing of personally relevant health messages. Personality and Social Psychology Bulletin 18: 669-679.

Lipkus IM, Eissenberg TE, Schwartz-Bloom RD, et al. (2013) Relationships among factual and perceived knowledge of harms of waterpipe tobacco, perceived risk, and desire to quit among college users. Journal of Health Psychology. Epub ahead of print 8 August 2013. DOI: $10.1177 / 1359105313494926$.

Maio GR and Thomas GM (2007) The epistemicteleologic model of deliberate self-persuasion. Personality and Social Psychology Review 11: 46-67.

Müller BCN, Van Baaren RB, Ritter SM, et al. (2009) Tell me why ... The influence of selfinvolvement on short term smoking behaviour. Addictive Behaviors 34: 427-431.

Murray CJ and Lopez AD (1997) Alternative projections of mortality and disability by cause 1990-2020: Global Burden of Disease Study. Lancet 349: 1498-1504.

Mussweiler T and Neumann R (2000) Sources of mental contamination: Comparing the effects of self-generated versus externally provided primes. Journal of Experimental Social Psychology 36: 194-206.

Peters G-JY, Ruiter RAC and Kok G (2012) Threatening communication: A critical re-analysis and a revised meta-analytic test of fear appeal theory. Health Psychology Review 7: S8-S31.

Petty ER and Cacioppo JT (1986) The elaboration likelihood model of persuasion. In: Berkowitz $\mathrm{L}$ (ed.) Advances in Experimental Social Psychology, Volume 19. New York: Academic Press, pp. 123-205.

Ruiter RAC and Kok G (2005) Saying is not (always) doing: Cigarette warning labels are useless. European Journal of Public Health 15: 329-330. 
Senay I, Albarracin D and Noguchi K (2010) Motivating goal-directed behavior through introspective selftalk: The role of the interrogative form of simple future tense. Psychological Science 21: 499-504.

Süssenbach P, Niemeier S and Glock S (2013) Effects of and attention to graphic warning labels on cigarette packages. Psychology \& Health 28(10): 1192-1206.

Tuakli N, Smith MA and Heaton C (1990) Smoking in adolescence: Methods for health education and smoking cessation: A MIRNET study. Journal of Family Practice 31: 369-374.

Wolburg J (2006) College students' responses to antismoking messages: Denial, defiance, and other boomerang effects. Journal of Consumer Affairs 40: 294-323.

World Health Organization (WHO) (2003) Final Text of WHO Framework Convention on Tobacco Control. Geneva: WHO. Available at: http://www.who.int/tobacco/en/ 